\title{
Effect of Air Cushion Seating in Passenger Car on different Road Conditions
}

\author{
Poodipeddi Krishna Kiran ${ }^{1, *}$ and Maganti Pramila Devi ${ }^{2}$ \\ ${ }^{1}$ Mechanical Engineering Department, Gayatri Vidya Parishd College of Engineering \\ (A), Visakhapatnam, A.P., India \\ 2Mechanical Engineering Department, Andhra University College of Engineering (A), \\ Visakhapatnam, A.P., India
}

Article Type: Article

Article Citation: Poodipeddi Krishna Kiran, Maganti Pramila Devi. Effect of air cushion seating in passenger car on different road conditions. Indian Journal of Science and Technology. 2020; 13(10), 1224-1231. D0l: 10.17485/ ijst/2020/v013i10/150099

Received date: February 19, 2020

Accepted date: March 2, 2020

*Author for correspondence:

Poodipeddi Krishna Kiran

krishnakiran@gvpce.ac.in P Mechanical Engineering Department, Gayatri Vidya Parishd College of Engineering (A), Visakhapatnam, A.P., India

\begin{abstract}
Objectives: To improve the ride comfort of the passenger car driver using an air-inflated cushion on top of the conventional polyurethane foam seat. Methodology: The acceleration between the base of the driver and the seat interface in a small passenger car is measured in all the three Cartesian directions for three different drivers each of different weights, on four different types of roads using SV106 Whole Body Vibration (WBV) measurement equipment. The car is driven at different speeds within the range of $20 \mathrm{kmph}$ to $80 \mathrm{kmph}$ on smooth road like highways and a limited maximum speed of 40 kmph on the other roads. The obtained results are used to calculate the percentage Seat Effective Amplitude Transmissibility (\%SEAT) to estimate the ride comfort. Findings: The results proved that by using the air-inflated seat cushion placing over the polyurethane seat cushion has decreased the vibration that is transmitted to the driver and the ride comfort is enhanced rather than using only polyurethane foam cushion that is provided by the manufacturer. The air-inflated cushion used is of compartmental celled model which will not get deflated easily assuring comfort for a long period of safe drive.
\end{abstract}

Keywords: Air-celled Cushion, Seat, Transmissibility, Ride-comfort, Whole Body Vibration.

\section{Introduction}

In the present-day scenario, cars have become the preferred means of transport since they offer independence, comfort, pollution-free ambience, and relative safety for the occupants. Ride comfort, of the driver, is hence receiving increasing attention from automobile manufacturers and researchers. Next to road quality-on which the car manufacturer has no control-seat design directly influences ride comfort. Base vibrations are created by the 
road profile, especially at high car speeds, and are transmitted to the chassis of the car. These vibrations are modified by the seat frame and are partly absorbed by the cushion material on top of the seat. Unfortunately, however, the remaining unabsorbed vibration is transmitted to the driver causing discomfort. Studies have proved that depending on the duration of drive, the vibrations imparted to human body may cause lower back pain and muscle fatigue and orthopedically related injuries [1,3]. Reducing the exposure of human body to vibrations gives a comfortable ride as well as decreases the chance of getting ill. This context has led the researchers to concentrate their studies on reducing the transmission of vibrations to occupants or drivers in automobiles to minimize the discomfort and improve the efficiency of driver [2]. Estimation of ride comfort can be done by measuring the vibration that is being imparted to the human being at the place of direct contact with the automobile, the amplitudes of the vibrations are measured and extensive studies were conducted in establishing the positive correlation between the root-mean-square ( $\mathrm{rms}$ ) of the vibrations transmitted in the vertical direction to the driver due to uneven roads [4]. Many experimentations have been carried out to reduce the transmissibility of vibrations to the human body, especially the driver in the passenger cars the researches have suggested different ways and methods to increase ride comfort through attenuation of vibrations transmitted to the driver by using active or passive isolation system [5-6], but improvising the suspension system may only help in reduction of vibration exposure but the peak acceleration frequencies harmful to human bodies are still transmitted [7] and moreover, it is a costly affair. ISO 2631-1 has defined a range of vibration frequencies which are harmful to the human body where they are amplified and also specified that the seat cushion characteristics significantly influence the transmissibility of vibrations. Thus the selection of cushion plays a vital role in imparting comfort to the driver [8]. In the present-day market, the users of automobiles especially cars are expecting more comfort in the compartment accordingly the seat cushions are designed for better ride comfort, sound absorption and durability [9]. Many attempts and experiments have been conducted to enhance the ride comfort by changing the cushion material and adding damping materials to the cushion. Usage of air-filled cushion was suggested in a study that compared the vibration damping performance of them with gel-based cushions and the former is proved to be good for precaution against lower back pain and spine disorders $[10,15]$. In a similar study, the air filled cushion is modeled and simulated using a quarter car model with three degree of freedom.

In the present study, multi-compartment of high interconnected air-celled cushion is placed over the polyurethane cushion that already exists in a small passenger car and the seat transmissibility are evaluated. Currently, estimation of the Seat Effective Amplitude Transmissibility (SEAT) value is a popular method used to evaluate seat comfort as the seat isolation efficiency for a base excitation can be assessed through it [12]. The accelerations on the seat surface i.e. in between the base of the driver and the seat interface are measured with the aid of SV106 whole-body vibration analyser and the \% SEAT values are calculated considering the r.m.s values of the amplitude measured for the subjects driving on different road conditions. 


\section{Method}

\subsection{Subjects}

Three healthy male individuals with body weight 65,75 , and $85 \mathrm{~kg}$ and of the average age group of 30 years have participated. All participants were right-handed and right foot dominant and had not previously experienced body disorders or illness, they also possess a valid driving licence.

\subsection{Equipment}

In this study, two seats, the seat being used in the Indian make small passenger hatchback model car and the same with a single compartment of high interconnected air-celled cushion over it were tested. The cushion of this air-celled seat is made of individual, interconnected air cells allowing air to transfer from chamber-to-chamber, evenly distributing body weight. A seat with seat pad accelerometer is shown in Figure 1 and with an air-celled cushion is shown in Figure 2.

For vibration measurement, a seat pad accelerometer of model SV 38 is placed on the seat surface and the accelerations were measured. Then the seat pad accelerometer is placed on the surface of the air cushion which is placed on the seat for measuring the same. To measure the floor acceleration tri-axial accelerometer of model Sv84 is used. Both the

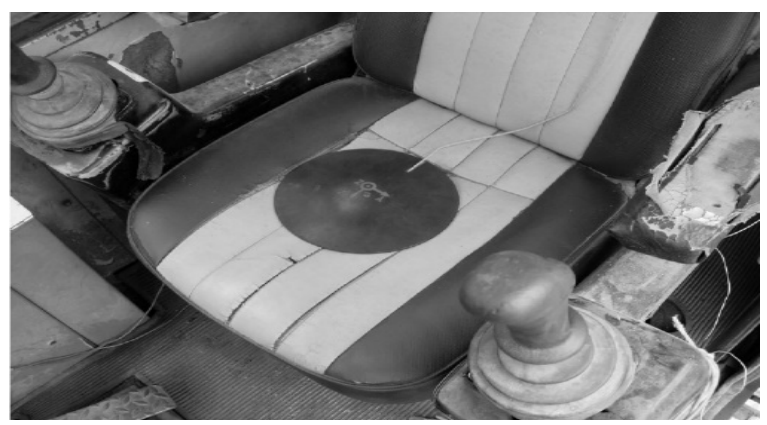

FIGURE 1. Seat with seat pad accelerometer.

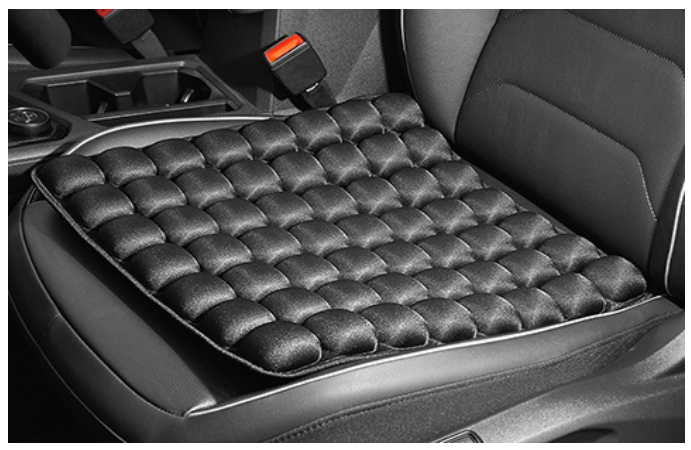

FIGURE 2. Seat with air-celled cushion. 
accelerometers are connected to the SV106 vibration accelerometer which is a dedicated vibration meter which interpret the results directly to match ISO-2631 [1] standards.

\subsection{Test Tracks}

The experiment with the subjects is conducted on three four different types of roads shown in the figure viz. highway, Belgian block paving, bumpy road and unpaved road shown named as roads A, B, C, and D are shown in Figures 3-6, respectively.

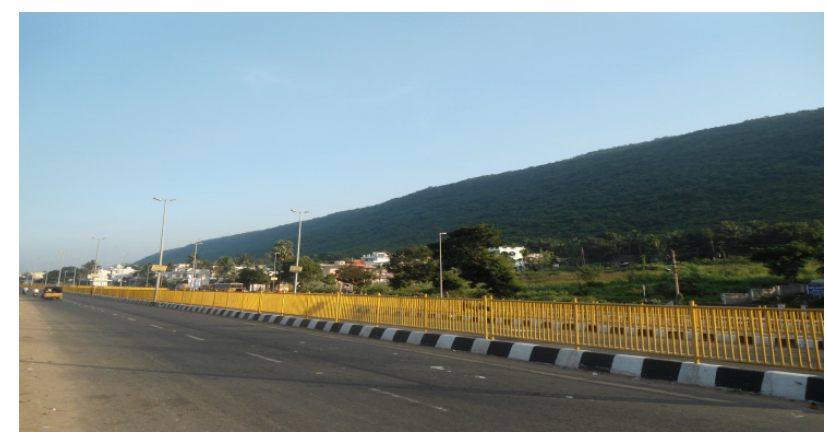

FIGURE 3. Road A.

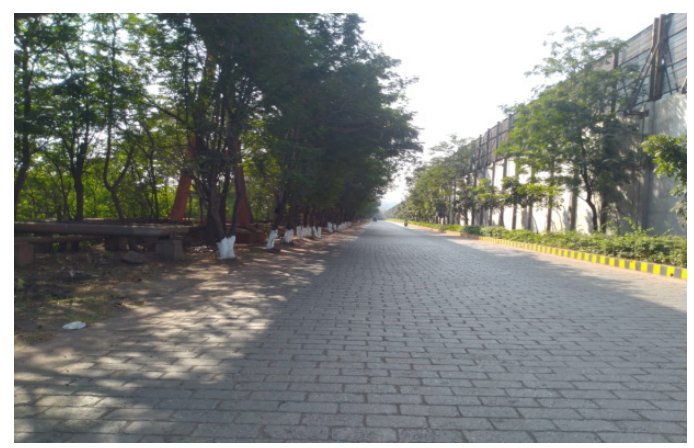

FIGURE 4. Road B.

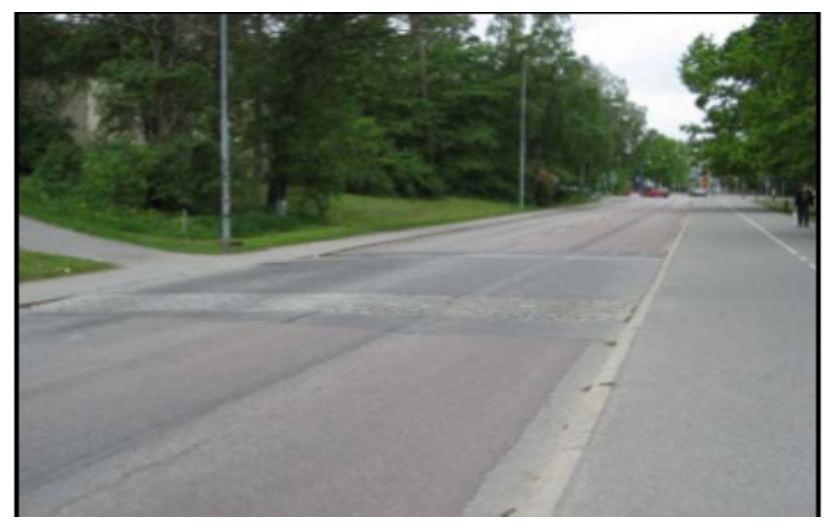

FIGURE 5. Road C. 


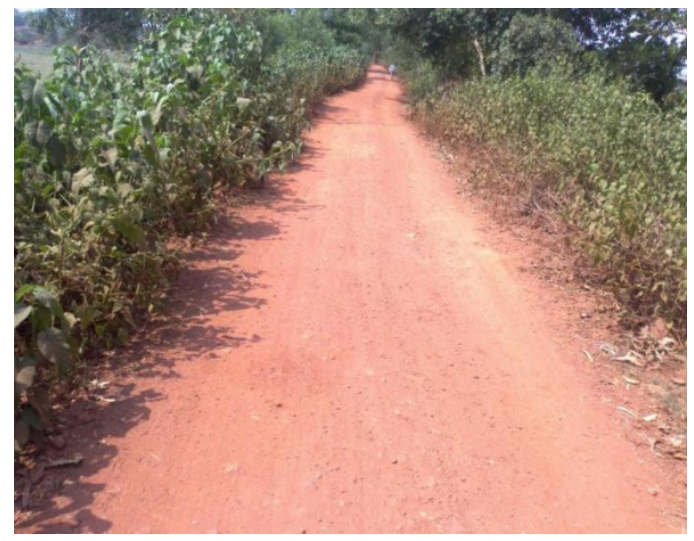

FIGURE 6. Road D.

\section{Experimentation}

On-road tests were performed to evaluate the ride comfort two tri-axial accelerometers were connected to the SV 106 vibration meter which is set to measure the r.m.s. acceleration in three Cartesian coordinate directions, namely X, Y, Z both on the floor of the car that is at a point on the chassis near to the seat base using tri-axial SV 84 accelerometer and then on the surface of the seat using SV 38 tri-axial seat pad accelerometer. First, the measurements were taken for the existing seat i.e. is without air cushion and the same was repeated with the seat on which the air cushion is placed. The experimentation was conducted with three different subjects of different weights ranging from $65 \mathrm{kgf}$ to $85 \mathrm{kgf}$ and on four different roads A, B, C, and D described in Table 1. Each subject has driven the car on all the four roads at different speeds ranging from $20 \mathrm{kmph}$ to $80 \mathrm{kmph}$ depending on the safe permissible speed limit of the road and feasibility of driving on the road. On Type A road, the test was conducted at four different speeds of the car mentioned in Table 1 which shows the feasible and permissible testing speeds on each road. Driving on the roads B, C, and D it is found to be very difficult over $40 \mathrm{kmph}$ speed because unavoidable traffic and public interruptions, and moreover, the road has more bumps and moderately paved. All the subjects have driven the car by wearing safety seat belts.

Accelerations along the three Cartesian axes i.e. $a_{\mathrm{wx}}, a_{\mathrm{wy}}, a_{\mathrm{wz}}$ were accelerations simultaneously measured for both seat and floor. The accelerations obtained were

TABLE 1. Description and feasible testing speeds of different roads chosen for test.

\begin{tabular}{clc}
\hline $\begin{array}{c}\text { Road } \\
\text { type }\end{array}$ & \multicolumn{1}{c}{ Description of the road } & $\begin{array}{c}\text { Permissible/feasible } \\
\text { speed limit in } \mathbf{k m p h}\end{array}$ \\
\hline A & Smooth highway & Up to 80 \\
B & rectangular quarried stone paved roads & Up to 40 \\
C & $\begin{array}{l}\text { Road consisting of a series of bumps } \\
\text { unpaved road made from the native material of the land }\end{array}$ & Up to 40 \\
D & $\begin{array}{l}\text { surface through which it passes } \\
\end{array}$
\end{tabular}


frequency weighted using the weighting curves $W_{\mathrm{k}}$ and $W_{\mathrm{k}}$ respectively for all the three Cartesian Directions. The vibration total value $a_{\mathrm{v}}\left(\mathrm{m} / \mathrm{s}^{2}\right)$ of r.m.s. weighted acceleration is calculated using Eq. (1) and Eq. (2) for seat and floor, respectively.

$$
\begin{gathered}
a_{v \text { seat }}=\sqrt{a_{w x(\text { seat })}^{2}+a_{w y(\text { seat })}^{2}+a_{z x(\text { seat })}^{2}} \\
a_{v_{\text {floor }}}=\sqrt{a_{w x(\text { floor })}^{2}+a_{w y(\text { floor })}^{2}+a_{z x(\text { floor })}^{2}}
\end{gathered}
$$

The values of $\left(a_{\mathrm{v}}\right)$ for seat and floor thus obtained are used to calculate \%SEAT in both the cases using Eq. (3)

$$
\% \text { SEAT }=\frac{a_{v_{\text {seat }}}}{a_{v_{\text {floor }}}} \times 100
$$

For a seat for which the vibrations are undammed the accelerations produced at the base are fully transmitted to the interface surface of driver and the seat indicating $100 \%$ SEAT value, decreasing values of \% SEAT indicate more comfortable seat [13-14]. Lesser the value of the \% SEAT more is the comfort.

\section{Results and Discussion}

The results depicted in Table 2 show that with the increase of the driver weight for the ride made without air-cushion the values of \% SEAT have increased indicating low comfort on road $\mathrm{A}$, when compared to the values of \% SEAT in Table 3 which shows the values for the ride with using an air cushion which is placed over the seat of the driver. For road B, C, D, there is no prominent decrease in the values of \% SEAT when compared to the decrement

\begin{tabular}{|c|c|c|c|c|c|c|c|c|c|c|c|c|}
\hline \multirow{5}{*}{$\begin{array}{l}\text { Road } \\
\text { type }\end{array}$} & \multicolumn{12}{|c|}{ Weight of the subject in kgf } \\
\hline & \multicolumn{4}{|c|}{65} & \multicolumn{4}{|c|}{75} & \multicolumn{4}{|c|}{85} \\
\hline & \multicolumn{12}{|c|}{ Speed of the car in kmph } \\
\hline & 20 & 40 & 60 & 80 & 20 & 40 & 60 & 80 & 20 & 40 & 60 & 80 \\
\hline & \multicolumn{12}{|c|}{$\%$ SEAT } \\
\hline $\mathrm{A}$ & 43.07 & 38.95 & 40.19 & 39.56 & 41.14 & 46.83 & 37.52 & 38.68 & 44.52 & 43.77 & 40.63 & 45.347 \\
\hline $\mathrm{B}$ & 31.84 & 27.14 & - & - & 37.25 & 31.17 & - & - & 35.95 & 29.28 & - & - \\
\hline $\mathrm{C}$ & 54.56 & 40.91 & - & - & 42.23 & 40.31 & - & - & 52.27 & 43.83 & - & - \\
\hline $\mathrm{D}$ & 41.93 & 35.55 & - & - & 40.02 & 33.74 & - & - & 44.53 & 41.28 & - & - \\
\hline
\end{tabular}
in $\operatorname{road} \mathrm{A}$.

TABLE 2. \% SEAT for different subjects on different roads without cushion 
TABLE 3. \% SEAT for different subjects on different roads with air-cushion over the seat

\begin{tabular}{|c|c|c|c|c|c|c|c|c|c|c|c|c|}
\hline \multirow{5}{*}{$\begin{array}{l}\text { Road } \\
\text { type }\end{array}$} & \multicolumn{12}{|c|}{ Weight of the subject in kgf } \\
\hline & \multicolumn{4}{|c|}{65} & \multicolumn{4}{|c|}{75} & \multicolumn{4}{|c|}{85} \\
\hline & \multicolumn{12}{|c|}{ Speed of the car in kmph } \\
\hline & 20 & 40 & 60 & 80 & 20 & 40 & 60 & 80 & 20 & 40 & 60 & 80 \\
\hline & \multicolumn{12}{|c|}{$\%$ SEAT } \\
\hline A & 36.77 & 33.64 & 37.07 & 38.14 & 40.11 & 38.61 & 35.85 & 35.53 & 43.27 & 37.38 & 38.32 & 42.03 \\
\hline B & 20.29 & 25.55 & - & - & 22.62 & 30.51 & - & - & 34.85 & 28.54 & - & - \\
\hline $\mathrm{C}$ & 44.99 & 37.89 & - & - & 31.32 & 32.3 & - & - & 47.72 & 41.83 & - & - \\
\hline $\mathrm{D}$ & 40.51 & 32.1 & - & - & 34.36 & 33.74 & - & - & 40.31 & 36.51 & - & - \\
\hline
\end{tabular}

The values of \% SEAT which are normalized over the weight of the driver as and the results have shown that the minimum transmissibility without cushion on Road A is observed at a speed of $60 \mathrm{kmph}$ and with cushion the transmissibility is minimum at 40 $\mathrm{kmph}$. It can be inferred that using of air-cushion is recommend at higher speeds on road A, which is smooth and of good quality. The bar chart for the results is shown in Figure 7.

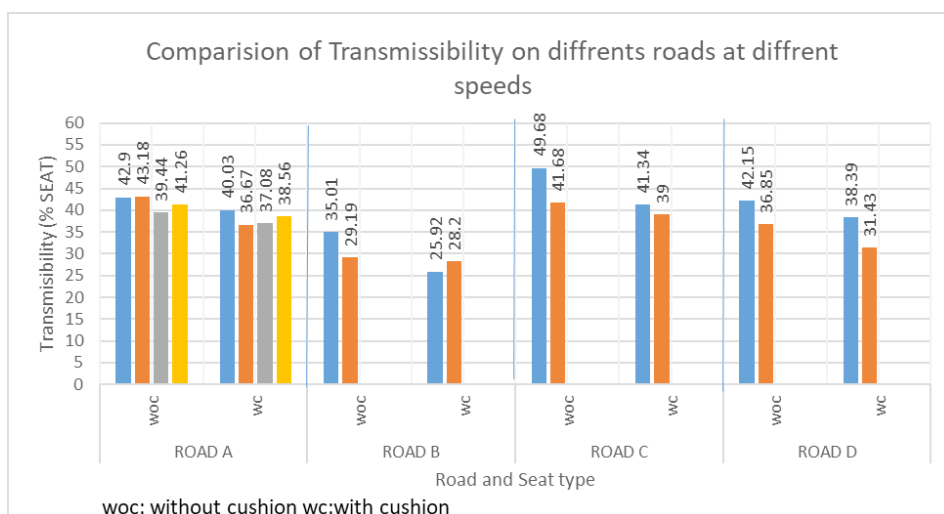

FIGURE 7. Comparison of transmissibility on different roads at different speeds.

\section{Conclusion}

Ride comfort in a passenger car is an important to be monitored in the present day world. Seat transmissibility is one of the important factors that effects the driver as the whole body vibrations are directly passed to the driver. Reduction of the vibration transmissibility through set to the driver minimizes the ill effects of WBV. Using an air-cushion over the seat has decreased the \% SEAT transmissibility at higher speeds on smooth paved roads like highways in a notable manner and is also an economical advisable solution to increase the ide comfort without altering the actual seat design. 


\section{References}

1. Hong KT., Hwang SH, Hong KS. Automotive ride-comfort improvement with an air cushion seat. Proceedings of SICE annual conference, Fukui. 2003, 2043-2048. DOI: 10.1.1.76.5424.

2. Karnopp DC, Crosby MJ, Harwood RA, Vibration control using semi-active force generators. ASME Journal of Engineering for Industry. 1974, 96(2), 619-626. DOI: 10.1115/1.3438373.

3. Kasara M, Shirazi-Aol A, Drouin G, Dynamics of human lumbar intervariable joints experimental and finite element investigation. Spine. 1997, 7. DOI: 10.1097/00007632-199201000-00014.

4. Wolf E, Pearlman J, Cooper RA, Fitzgerald SG, Kelleher A, Collins DM, Boninger ML, Cooper R. Vibration exposure of individuals using wheelchairs over sidewalk surfaces. Disability and Rehabilitation. 2005, 27(23), 1443-1449. [PMID: 16418059] http://dx.doi. org/10.1080/09638280500264709

5. Aye SA, Heyns PS. The evaluation of whole-body vibration in a South African opencast mine. The Journal of the Southern African Institute of Mining and Metallurgy. 2011, 111. https://doi. org/10.4271/2016-28-0203

6. Rao Singiresu S. Mechanical vibrations. 5th edn. Pearson Education Inc. 2011.

7. Cooper RA, Wolf E, Fitzgerald SG, Boninger ML, Ulerich R, Ammer WA, Seat and footrest shocks and vibrations in manual wheelchairs with and without suspension. Archives of Physical Medicine and Rehabilitation. 2003, 84(1), 96-102. [PMID: 12589628] http://dx.doi.org/10.1053/ apmr.2003.50069

8. ISO 2631-1. Mechanical vibration and shock, evaluation of human exposure to whole-body vibrations. Part 1: general requirements. International Organization for Standardization: Geneva (Switzerland). 1997. https://www.iso.org/standard/7612.html.

9. Broos R, Sonney JM, Thanh HP, Casati FM. Polyurethane foam molding technologies for improving total passenger compartment comfort. Proceedings of the 2000 API polyurethane conference, Technomic: Lancaster. 2000. 341-353. https://pdfs.semanticscholar.org/69a1/f91a 23060f5f721f9f937332922e7a378178.pdf

10. Yasmin Garcia-Mendez BS, Jonathan L. Pearlman, Rory A. Cooper, Michael L. Boninger. Dynamic stiffness and transmissibility of commercially available wheelchair cushions using a laboratory test method. JRRD. 2012, 49(1), 7-22. https://www.herl.pitt.edu/jrrd/1610-Garcia_ Cushions_JRRD.pdf.

11. Kyung-Tae Hong, Su-Hwan Hwang, and Keum-Shik Hon. Automotive ride-comfort improvement with an air cushion seat. In: SICE annual conference, Fukui. 2003. https://www. researchgate.net/publication/250145311.

12. Griffin MJ. Handbook of human vibration. Academic Press: London. 1990.

13. van Niekerka JL, Pielemeierb WJ, Greenberg JA. The use of seat effective amplitude transmissibility (SEAT) values to predict dynamic seat comfort. Journal of Sound and Vibration. 2002, 260(2003), 867-888. DOI: 10.1016/S0022-460X(02)00934-3.

14. Roberto Deboli, Angela Calvo, Christian Preti. Whole-body vibration: measurement of horizontal and vertical transmissibility of an agricultural tractor seat. International Journal of Industrial Ergonomics. 2017, 58. https://doi.org/10.1016/j.ergon.2017.02.002.

15. Park SJ, Subramaniyam M, Kim SE, Kim TH, Sin HS, Seo DH, ... Lee JC. Enhancement of automotive seating comfort using double-wall 3D air mat cushion. SAE Technical Paper Series. 2016. DOI: $10.4271 / 2016-01-1430$. 